Ola P. Rosaeg MB FRCPC, Anne C.P. Lui MD FRCPC, Nicholas J. Cicutti PhD, Paul R. Bragg MD FRCPC, Mary-Lou Crossan BA MLT, Barbara Krepski RN

\section{Peri-operative multi- modal pain therapy for Caesarean section: analgesia and fitness for discharge}

Purpose: To compare, the efficacy of a multi-modal analgesic regimen and single drug therapy with iv PCA morphine after Caesarean delivery with spinal anaesthesia.

Methods: Forty ASA I-2 parturients presenting for elective Caesarean section were randomized to receive multimodal pain treatment with intrathecal morphine, incisional bupivacaine and ibuprofen + acetaminophen po until hospital discharge (Group I) or conventional therapy with iv PCA morphine weaned to acetaminophen + codeine po. (Group 2). Both groups received spinal anaesthesia with $1.7 \mathrm{ml}$ hyperbaric bupivacaine $0.75 \%$. Visual analog pain scores at rest (RVAPS) and with movement (DVAPS) were recorded q $2 \mathrm{hr}$ during the first $24 \mathrm{hr}$, then $\mathrm{q} 4 \mathrm{hr}$ until discharge. Time to first walking, eating solid food, flatus, bowel movement, voiding and hospital discharge were recorded.

Results: Pain scores were lower in Group I patients during the first $24 \mathrm{hr}$ after spinal injection RVAPS $0.6 \pm 0.1$ in Group I vs $2.1 \pm 0.1$ in Group 2 (mean \pm SEM). DVAPS $1.9 \pm 0.1$ in Group I vs $4.1 \pm 0.1$ in Group 2 ( $P<$ $0.0001)$. Times to first flatus, $36.1 \mathrm{hr} \pm 2.9$ vs $20.5 \pm 1.8(P<0.05)$ and to first bowel movement, $74.8 \mathrm{hr} \pm 5.6$ vs $57.4 \pm 4.7(P<0.0001)$ were longer in Group 2 patients. There was no difference between groups in time to eating solid food, walking or hospital discharge.

Conclusion: Multi-modal pain therapy resulted in improved early post-operative analgesia during the first $24 \mathrm{hr}$ after Caesarean delivery. Patients receiving i PCA morphine followed by acetaminophen + codeine po were more likely to develop decreased bowel mobility. All patients, with one exception, achieved discharge criteria (eating solid food, absence of nausea, normal lochia, dry incision and DVAPS < 4) at $48 \mathrm{hr}$ after spinal injection.

Objectif : Comparer l'efficacité d'une association de méthodes analgésiques avec celle de la morphine en PCA après la césarienne sous rachianesthésie.

Méthodes : Quarante parturientes ASA I-2 programmées pour une césarienne non urgente ont été réparties aléatoirement pour recevoir une analgésie combinant plusieurs méthodes (rachidienne à la morphine, infiltration à la bupivacaine du site de la laparotomie et ubiprofène + acétaminophène po jusqu'au congé (Groupe 1) ou un traitement conventionnel à la morphine iv en PCA avec sevrage pour l'acétaminophène + codéine po (Groupe 2). Les deux groupes avaient reçu une rachianesthésie avec $1,7 \mathrm{ml}$ de bupivacaïne $0,75 \%$ hyperbare. Les scores de douleur au repos sur une l'échelle visuelle analogique (RVAPS) et avec mouvements (DVAPS) ont été enregistrés q2h pendant $24 \mathrm{~h}$, ensuite q4h jusqu'au congé. Lintenalle jusqu'à l'ambulation, l'alimentation solide, la reprise des gaz et des matières, la miction et jusqu'au congé hospitalier a été enregistré.

Résultats : Pendant la période de $24 \mathrm{~h}$ suivant la rachianesthésie, les scores sur l'ÉVA (moyenne \pm SEM) étaient inférieurs dans le groupe I à ceux du groupe 2 (RVAPS $0,6 \pm 0,1$ is $2,1 \pm 0,1$ et DVAPS $1,9 \pm 0,1$ vs $4,1 \pm 0,1$ : $P<0,0001)$. La reprise des gaz $(36,1 \pm 2,9 \mathrm{~h}$ vs $20,5 \pm 1,8 \mathrm{~h} ; P<0,05)$ et la première selle $(74,8 \pm 5,6 \mathrm{~h}$ vs 57,4 $\pm 4,7 \mathrm{~h} ; P<0,0001$ ) étaient plus tardives dans le groupe 2 . Le retour à l'alimentation solide, à l'ambulation et le moment du congé ne différait pas.

Conclusion : L'association de plusieurs méthodes thérapeutiques permet d'améliorer l'analgésie postopératoire pendant les $24 \mathrm{~h}$ qui suivent la césarienne. La PCA à la morphine suivie d'acétaminophène + codéine po offre un plus grand risque de diminution de la motilité intestinale. Toutes les patientes, à une exception près, ont atteint les critères du congé (alimentation solide, absence de nausées, lochies normales, plaie tarie et DVAPS < 4) $48 \mathrm{~h}$ après la rachianesthésie. 


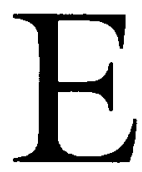
FFECTIVE pain therapy after Caesarean delivery is important for comfort and to allow early ambulation to facilitate care of the newborn. In addition, optimization of postoperative pain treatment could allow early return to a regular diet and normal bladder and bowel function, thus facilitating early discharge from hospital. Concurrent intrathecal administration of morphine $(0.25-0.5 \mathrm{mg})$ with hyperbaric bupivacaine for Caesarean delivery can provide post-operative analgesia for up to $27 \mathrm{hr}^{1-3}$ Nevertheless, a considerable proportion of patients require supplemental oral or parenteral analgesics during the first $24 \mathrm{hr}$ after surgery and subsequent days until discharge from hospital..$^{2-3}$ The adjunct administration of non-steroidal anti-inflammatory drugs (NSAID) in addition to neuraxial morphine provides superior pain relief to neuraxial morphine alone during the first $24 \mathrm{hr}$ after Caesarean delivery. ${ }^{4-6}$ Kehlet and Dahl ${ }^{7-9}$ have emphasized that effective postoperative pain relief with low incidence of side-effects can only be achieved by a combination of analgesics with different mechanisms of action, preferably administered before surgical incision. Improved pain relief will enable earlier mobilization and return of organ function. The concept of pre-emptive analgesia became popular after experimental studies demonstrated that pre-operative local anaesthetic or opioid administration could prevent central hyperexcitability. ${ }^{10,11}$ Clinical studies have resulted in conflicting results regarding the potential advantage of pre-incision $v s$ post-operative analgesia. ${ }^{9}$ However, Negre et al. ${ }^{12}$ demonstrated a preemptive analgesic effect from pre-operative administration of epidural morphine.

Although there is much data on the analgesic efficacy of a specific drug alone or in combination with one other drug, there are no data on the efficacy of multimodal pain management on the post-operative outcome of patients after Caesarean section. Therefore, we decided to investigate, in a prospective fashion, the efficacy of a multi-modal analgesic regimen and its effect on mobilization, return of bowel and bladder function, solid food intake and incidence of side-effects. We also examined the times to achieve medical criteria for hospital discharge in the two study groups. In a pilot study we had determined that all women discharged following Caesarean delivery with conventional iv PCA morphine and acetaminophen + codeine regimen had a dynamic pain score (DVAPS) of $<4$ at the time of hospital discharge.

\section{Methods}

The study protocol was approved by the Research Ethics Committee at the Ottawa Civic Hospital. Written informed consent was obtained from 40 ASA I or II women scheduled for elective Caesarean section at term ( $>37 \mathrm{wk}$ gestation). Exclusion criteria included allergy to any of the study medications, age $<18 \mathrm{yr}$, poor communication in English, history of substance abuse or contraindication to spinal anaesthesia.

Patients were assigned, according to a computer generated set of random numbers, into one of two study groups; experimental multi-modal (Group 1) or control iv PCA morphine (Group 2). No premedication was administered except $30 \mathrm{ml} 0.3 \mathrm{M}$ sodium citrate po. Ringer's lactate solution $15 \mathrm{ml} \cdot \mathrm{kg}^{-1}$ iv was infused over $15 \mathrm{~min}$ before intrathecal injection of drugs. Spinal anaesthesia was induced in the sitting position at $\mathrm{L}_{2-3}$ or $\mathrm{L}_{3-4}$ interspace using a \#27 Quincke spinal needle. Aspiration of clear CSF was obtained after dural puncture and also after drug injection. All patients received $1.7 \mathrm{ml}$ hyperbaric bupivacaine $0.75 \%$. For women in Group $1,0.3 \mathrm{ml}(\mathrm{mg}$ ) of preservative-free morphine was added to the bupivacaine solution. Intra-operative monitoring included pulse oximetry, ECG and automated non-invasive blood pressure monitoring. All parturients received $3 \mathrm{~L} \cdot \mathrm{min}^{-1} \mathrm{O}_{2}$ by nasal cannula until delivery of the infant. Metoclopramide $10 \mathrm{mg}$ and $25 \mathrm{mg}$ dimenhydrinate iv were administered prophylactically to women in both study groups after delivery of the infant to reduce the incidence of nausea and vomiting. Intra-operative hypotension was treated with increments of ephedrine iv at the discretion of the attending anaesthetist. Fentanyl and midazolam iv were available, at the request of the patients, for intra-operative pain and anxiety respectively. Parturients in Group 1 received $20 \mathrm{ml}$ plain bupivacaine $0.25 \%$ to fascia and a further $20 \mathrm{ml}$ to skin edges prior to wound closure. Acetaminophen $650 \mathrm{mg}$ po $\mathrm{q} 4 \mathrm{hr}$ and $400 \mathrm{mg}$ ibuprofen po $\mathrm{q} 4 \mathrm{hr}$ on a regular, around the clock schedule was initiated three hours after spinal injection and continued until hospital discharge. Codeine 30$60 \mathrm{mg} p o \mathrm{q} 4 \mathrm{hr}$ was available on request if pain relief with the experimental regimen was inadequate. Both groups were given diphenhydramine for treatment of pruritus and dimenhydrinate for nausea or vomiting. Respiratory rate was monitored every hour during the first $24 \mathrm{hr}$ after surgery. Patients from both study groups were transferred to the post-partum ward three hours after spinal injection. The ip infusion was discontinued prior to transfer and converted to a saline lock (Group 1). Intravenous PCA morphine was started in the recovery room 90 min after injection of intrathecal bupivacaine for patients in Group 2. The PCA bolus dose was $1.0 \mathrm{mg}$ with a lock-out interval of five minutes without background infusion or four hour limit. Patients in Group 2 were weaned from iv PCA morphine to $650 \mathrm{mg}$ acetaminophen $+60 \mathrm{mg}$ 
codeine po as per standard protocol (when using two requests in four hours).

Visual analog pain scores $(0=$ no pain and $10=$ worst possible pain) were obtained both at rest (RVAPS) and with movement or ambulation (DVAPS) q $2 \mathrm{hr}$ for $24 \mathrm{hr}$, and thereafter $\mathrm{q} 4 \mathrm{hr}$ until discharge from hospital. Supplemental codeine po consumption was recorded in Group 1, and PCA morphine iv consumption in Group 2 patients was retrieved from the PCA device using a text printer. The total post-operative consumption of diphenhydramine and dimenhydrinate was recorded. Unrestricted intake of solid food was allowed in both groups. A "Diet Advancement Record" recorded the type of food ingested and the incidence of side-effects (nausea, vomiting and pruritus). The urinary catheter was removed three hours after intrathecal injection in both groups, prior to discharge to the post-partum ward. Patients in both groups were allowed activity as tolerated when the sensorimotor block had regressed. The "Activity Milestone Questionnaire" recorded time to first voiding, flatus, bowel movement and walking. A record was made every six hours of status of incision/dressing and whether lochia were considered normal. Prior to discharge the women were asked to indicate the degree of overall satisfaction with post-operative pain management on a four point satisfaction scale: $(0=$ unsatisfied/poor, 1 =somewhat satisfactory, $2=$ satisfactory/adequate, $3=$ very good, $4=$ excellent). Finally, discharge readiness was assessed using post-Caesarean section discharge criteria (Table I). All parturients had to satisfy all six criteria before considered fit for hospital discharge.

In conforming with our working hypothesis, we estimated a $50 \%$ reduction in the mean resting and dynamic VAPS scores in Group 1 relative to Group 2 over the initial $24 \mathrm{hr}$ post-surgery. Assuming an $\alpha$ of 0.5 and $(1-B)$ of 0.8 , a total of 40 patients (20 per group) were required at the stated level of statistical confidence. Demographic data and analgesic consumption were analysed using Student's $t$ test. The VAPS scores were analysed using repeated measures analysis of variance (ANOVA). Discrete data and proportions were analysed using chi-square tests with Yates continuity correction for respective $2 \times 2$ contingency tables. $P<0.05$ was considered statistically significant.

TABLE I Post-Caesarean section discharge criteria

\author{
Eating solid food \\ Absence of nausea \\ Voiding \\ Normal lochia \\ Dry incision/dressing \\ Dynamic VAPS <4
}

\section{Results}

Two patients were lost to analysis due to break in study protocol (urinary catheter left in-situ beyond three hours after intrathecal injection), and another was withdrawn due to post-dural puncture headache. Three further patients were recruited and classified according to the randomization table. Therefore, a total of 40 patients were available for analysis; 21 patients in the multi-modal group and 19 in the control, iv PCA morphine, group.

There were no differences between groups with respect to age, weight, gravity, parity or gestational age. None of the patients in Group 1 received fentanyl or midazolam iv intra-operatively. Two patients in Group 2 each received $100 \mu \mathrm{g}$ fentanyl $i v$ after delivery of the infant, and four other patients in Group 2 required 1.0 $\mathrm{mg}$ midazolam $i v$ for anxiety during surgery.

Pain assessments obtained during the first $24 \mathrm{hr}$ after surgery showed that average pain scores at rest as well as pain scores over time were lower in Group 1 than in Group 2 (Figure a, Table IIa) $P<0.0001$. Dynamic pain scores were also lower in Group 1 than in Group 2 (Figure b, Table IIb). There were no
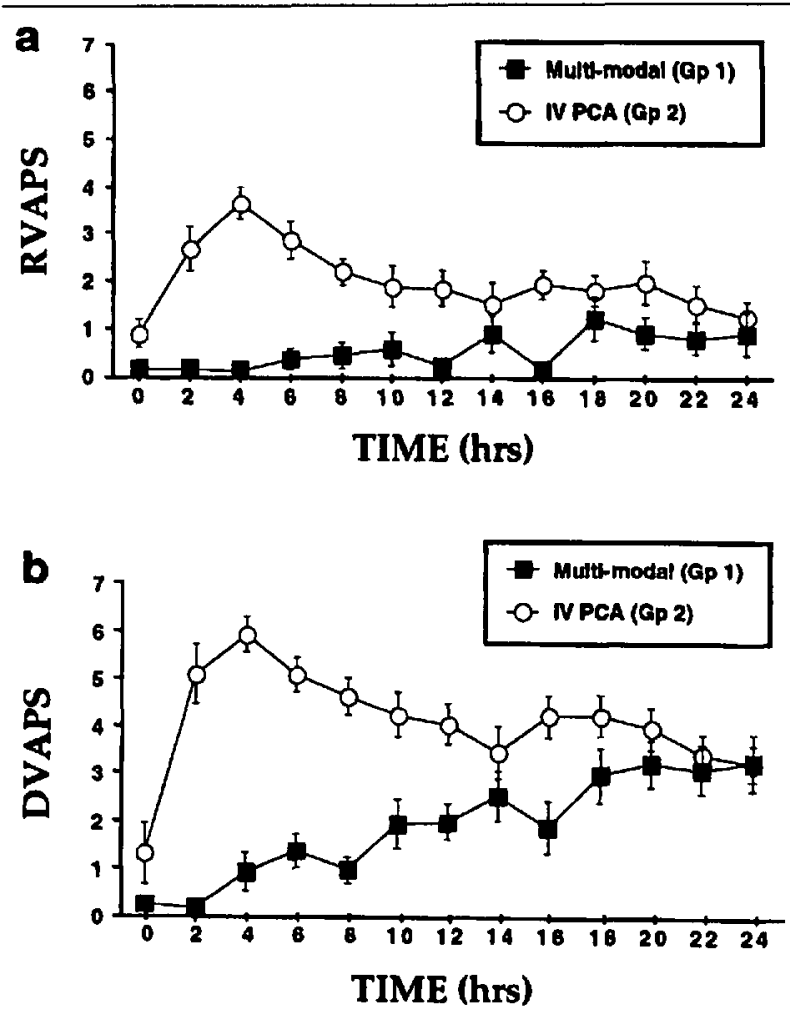

FIGURE Graphical representation of visual analog pain scores during first $24 \mathrm{hr}$ after sugery in multi-modal (Gp l) and IV PCA (Gp 2). Values indicate mean $\pm 95 \%$ confidence limits.

a) Resting (RVAPS)

b) With movement or ambulation (DVAPS)

In both situations pain scores were lower in $\mathrm{Gp} 1$ than in $\mathrm{Gp} 2$, $(P<0.0001)$. 
TABLE II a RVAPS during post-operative period until hospital discharge

\begin{tabular}{lllllll}
\hline Time & $0-24 \mathrm{br}$ & $24-48 \mathrm{br}$ & at $48 \mathrm{br}$ & $48-72 \mathrm{br}$ & $72-96 \mathrm{br}$ & Discharge \\
\hline Group 1 $(\mathrm{n}=21)$ & $0.6 \pm 0.1^{\star}$ & $1.0 \pm 0.2$ & $0.9 \pm 0.3$ & $1.0 \pm 0.2$ & $0.6 \pm 0.1$ & $0.5 \pm 0.2$ \\
Group 2 $(\mathrm{n}=19)$ & $2.1 \pm 0.1$ & $1.5 \pm 0.2$ & $0.9 \pm 0.2$ & $1.0 \pm 0.1$ & $0.5 \pm 0.1$ & $0.4 \pm 0.1$ \\
\hline
\end{tabular}

Mean \pm SEM

${ }^{\star} P<0.0001$

TABLE II b DVAPS during post-operative period until hospital discharge

\begin{tabular}{lllllll}
\hline Time & $0-24 \mathrm{br}$ & $24-48 \mathrm{br}$ & at $48 \mathrm{hr}$ & $48-72 \mathrm{br}$ & $72-96 \mathrm{hr}$ & Discharge \\
\hline Group 1 $(\mathrm{n}=21)$ & $1.9 \pm 0.1^{*}$ & $3.3 \pm 0.2$ & $2.9 \pm 0.5$ & $3.4 \pm 0.2$ & $2.9 \pm 0.3$ & $2.6 \pm 0.4$ \\
Group 2 $(\mathrm{n}=19)$ & $4.1 \pm 0.1$ & $3.4 \pm 0.2$ & $2.8 \pm 0.3$ & $2.6 \pm 0.2$ & $2.0 \pm 0.2$ & $2.1 \pm 0.4$ \\
\hline
\end{tabular}

Mean \pm SEM

$* P<0.0001$

TABLE III Side Effects (0-24 hr). Number of patients (percentage)

\begin{tabular}{lll}
\hline & $\begin{array}{l}\text { Group 1 } \\
(\mathrm{n}=21)\end{array}$ & $\begin{array}{l}\text { Group 2 } \\
(\mathrm{n}=19)\end{array}$ \\
\hline Nausea & $9(43)$ & $9(47)$ \\
Vomiting & $8(38)^{\star}$ & $2(10)$ \\
Pruritus & $16(76)^{\star}$ & $8(42)$ \\
\hline
\end{tabular}

${ }^{*} P<0.05$ Group 1 vs Group 2

TABLE IV Activity milestones. Mean \pm SEM or number of patients (percent)

\begin{tabular}{lll}
\hline & $\begin{array}{l}\text { Group I } \\
(\mathrm{n}=21)\end{array}$ & $\begin{array}{l}\text { Group 2 } \\
(\mathrm{n}=19)\end{array}$ \\
\hline Time to first hunger (hr) & $12.2 \pm 2.7$ & $\mathbf{1 0 . 1} \pm 1.9$ \\
Time to eating solid food (hr) & $12.1 \pm 1.7$ & $13.6 \pm 2.4$ \\
Time to first flatus (hr) & $20.5 \pm 1.8^{\star}$ & $36.1 \pm 2.9$ \\
Time to first bowel movement (hr) & $\mathbf{5 7 . 4} \pm 4.7^{\dagger}$ & $74.8 \pm 5.6$ \\
Time to spontancous voiding (hr) & $16.4 \pm 1.6$ & $11.6 \pm 2.4$ \\
Duration of hospital stay (hr) & $\mathbf{8 6 . 3} \pm 3.2$ & $\mathbf{8 5 . 8} \pm 3.09$ \\
Patients requiring "in-out" bladder & & \\
catheterization & $\mathbf{1 4 ( 6 7 \% ) ^ { \dagger }}$ & $\mathbf{5 ( 2 6 \% )}$ \\
\hline
\end{tabular}

${ }^{*} P<0.0001$

$\dagger P<0.05$

differences between groups in pain at rest or when walking after the first post-operative day until discharge from hospital. (Table II)

There was no difference between groups in the incidence of nausea, but vomiting occurred more frequently in women in Group 1 (Table III). The incidence of pruritus was higher in Group I (Table III), which was also reflected in the number of patients receiving diphenhydramine, ten in Group 1 and two in Group 2 $(P<0.05)$. There was no difference between groups in time to first experiencing hunger or time to eat solid food (Table IV). Time to first flatus and time to first bowel movement was shorter in Group 1 than in
Group 2 (Table IV). More women in Group 1 required temporary ("in-out") urinary catheterization than women in Group 2 (Table IV), but time to first spontaneous voiding was similar in both groups. The mean duration of $i v$ PCA therapy in Group 2 was $31.6 \mathrm{hr} \pm$ 10.1 (SD). Mean iv PCA morphine consumption was $82.7 \mathrm{mg} \pm 30.9$. Only seven of the 21 women in Group 1 received codeine $p o$; mean codeine consumption among these seven patients was $222.9 \mathrm{mg} \pm 188.8$. The duration of the post-operative stay was not different between groups (Table IV). There was no difference between groups in satisfaction with the two pain management regimens. There were no patients with a respiratory rate $<\mathbf{1 0}$ in either study group. Finally, no instances of wound dehiscence or abnormal lochia were found in any study patient.

\section{Discussion}

Our results indicate superior pain relief both at rest and with ambulation with a combination of intrathecal morphine, wound infiltration with bupivacaine plus ibuprofen and acetaminophen $p o$ than with conventional $i v$ PCA morphine therapy during the first 24 hr after surgery. Pain scores on subsequent days were not different between the experimental group receiving ibuprofen + acetaminophen and the control group receiving iv PCA morphine or acetaminophen + codeine (Table II).

Multi-modal and pre-emptive analgesic regimens have been recommended to prevent and improve pain relief after surgery, and reduce drug related side-effects. ${ }^{8,9}$ Previous studies have shown effective, long-lasting pain relief (up to $27 \mathrm{hr}$ ) from the addition of morphine to hyperbaric bupivacaine for intrathecal administration prior to Caesarean section..$^{1-3}$ In order to prevent breakthrough pain during the first $24 \mathrm{hr}$ after surgery and to provide pain relief beyond the duration of action of 
intrathecal morphine we decided to add an NSAID as an adjunct analgesic. Intramuscular diclofenac ${ }^{4}$ and ketoro$\mathrm{lac}^{5}$ and rectal administration of indomethacin ${ }^{6}$ have been shown to improve post-Caesarean analgesia after neuraxial morphine administration. We chose ibuprofen since it is approved for administration to lactating women, ${ }^{13}$ and can be given orally. Ibuprofen inhibits cyclooxygenase activity in the peripheral tissue at site of surgical trauma, thus reducing peripheral nociceptive input. Acetaminophen inhibits cyclooxgenase activity in the central nervous system. Acetaminophen given alone provides considerable analgesia after Caesarean delivery. ${ }^{14}$ The co-administration of ibuprofen and acetaminophen is safe as the pharmacokinetic disposition of the individual drugs is not altered. ${ }^{15}$ Our study did not show any complications associated with NSAID therapy. In particular there was minimal post-partum bleeding in any of the women.

Clinical studies of the analgesic effect of wound infiltration with local anaesthetic during Caesarean delivery have produced conflicting results. Trotter et al. ${ }^{16}$ failed to show a reduction in post-operative pain after Caesarean section using $20 \mathrm{ml}$ bupivacaine $0.5 \%$ sc. In contrast, Ganta et al. ${ }^{17}$ found that wound infiltration with $20 \mathrm{ml}$ bupivacaine $0.5 \%$ reduced pain scores and analgesic requirements for up to $12 \mathrm{hr}$ after surgery.

Although the efficacy of the individual analgesics have been studied after Caesarean delivery (intrathecal morphine,${ }^{1-3}$ acetaminophen,${ }^{14}$ NSAID,${ }^{4-6}$ incisional bupivacaine ${ }^{16,17}$ ), their relative contribution towards overall pain relief in the multi-modal study group is unknown. This was not the objective of the study. Instead, we chose a multi-modal drug combination designed to reduce sensitization of pain receptors (ibuprofen), decrease nociceptive input to the spinal cord via afferent peripheral nerves from surgical site (bupivacaine), inhibit pain transmission in the substantia gelatinosa (intrathecal morphine) and central nervous system (acetaminophen). This combination therapy avoided parenteral opioid administration during the entire post-operative period and attachment of intravenous infusion tubing with a PCA device. A recent study by Rosaeg and Lindsay ${ }^{18}$ showed that some post-Caesarean women with iv PCA therapy felt that the apparatus per se impeded their mobility. We chose patients receiving iv PCA morphine followed by acetaminophen + codeine $p o$ as a control group, because this is a popular and common analgesic regimen after Caesarean section with spinal anaesthesia.

There was no difference in time until first walking, despite the more intense pain relief experienced by the women in Group 1 immediately after surgery. The women in Group 1 did not utilize the effective early pain relief to mobilize earlier than the women in the control group who had more pain during the first 24 hr after surgery. Our finding that improved pain relief did not result in earlier mobilization was surprising, but Møiniche $e t a l .{ }^{19}$ found similar results when using balanced analgesia after major orthopaedic surgery. They concluded that improved postoperative pain relief per se did not result in earlier ambulation and patient activity. They suggested that conservative attitudes and routines in post-operative care may have limited mobilization and activity. In a subsequent study of patients undergoing colonic surgery they found that balanced analgesia and enforced oral feeding and mobilization did reduce convalescence and hospital stay after operation. ${ }^{20}$ Stenkamp ${ }^{21}$ et al. has suggested that intrathecal morphine administered at Caesarean section is associated with shorter hospital stay than women receiving parenteral morphine after surgery. The difference between length of hospital stay in the intrathecal morphine group (93 hr $\pm 21 \mathrm{hr}$ ) and the parenteral morphine group (102 hr $\pm 26 \mathrm{hr}$ ), while statistically significant, is not of major clinical relevance. Their study also suffered from methodological flaws which might have biased the study results. The investigation was a retrospective chart review and compared parturients having received intrathecal morphine with historic controls who had received iv or im morphine for post-operative pain relief.

Patients in both study groups started eating solid food at a similar time after surgery. Early oral feeding has been found to be safe and there is no need to restrict food until first flatus. ${ }^{22}$ Our results indicate that return of bowel motility (time to first flatus) was delayed in the iv PCA morphine group. La Rosa ${ }^{23}$ has suggested that large amounts of iv opioids in the early post-Caesarean period led to adynamic ileus in $23 \%$ of parturients. Time to first bowel movement was also longer in women in Group 2, thus confirming the negative effect of $i v$ morphine (and codeine po) on bowel morility.

Patients in both study groups had their urinary catheters removed three hours after intrathecal injection, in order to study the effect of surgery and analgesic therapy on bladder function. In addition, we considered that the urinary catheter might be an impediment to mobilization. More women in the multi-modal group required temporary re-catheterization before spontaneous voiding. Neuraxial morphine administration is associated with urinary retention. ${ }^{24}$ Further investigations are required to determine the optimal time to remove the urinary catheter after Caesarean delivery with and without neuraxial morphine.

The pain scores (at rest and walking) experienced by women, in both Group $I$ and Group 2, two days 
after surgery (at $48 \mathrm{hr}$ ) were not different from pain scores obtained prior to hospital discharge (Table II). However, since all the patients, with one exception, met the criteria for discharge $48 \mathrm{hr}$ after surgery, and had similar pain scores at $48 \mathrm{hr}$ compared with pain scores at discharge one can conclude that most women in both study groups could have been discharged two days after surgery. The woman who did not meet discharge criteria at $48 \mathrm{hr}$ had minor serosanginous oozing from the incision. Patients were not automatically discharged when discharge criteria were met. Possible explanations for the delay in time to actual discharge include: lack of enforcement of such criteria, conservative routines and attitudes by nurses and obstetricians, time required for breast-feeding instruction and social reasons (e.g., sick infant in neonatal intensive care unit).

In conclusion, we have described a simple, effective and safe multi-modal combination of analgesic drugs that resulted in superior early post-operative pain relief, allowing early mobilization and oral feeding. Patients receiving single drug therapy with iv PCA morphine had more discomfort at rest and with movement than did patients receiving multi-modal pain therapy in the initial post-operative period. Also, iv PCA morphine therapy inhibited bowel motility and may thus predispose to constipation in post-Caesarean women. Multimodal analgesia which includes neuraxial morphine is, however, associated with an increased incidence of pruritus, and may necessitate bladder catheterization beyond three hours after surgery. Future research in this area should also focus on the organizational aspects of post-partum care, since effective pain management did not alter time to discharge from hospital. Improved nurse education, availability of out-patient facilities for breast-feeding instruction and early post-operative follow-up and removal of surgical skin staples or sutures could possibly facilitate earlier hospital discharge after Caesarean delivery.

\section{References}

1 Abboud TK, Dror A, Zhu J, et al. Mini-dose intrathecal morphine for the relief of post-cesarean section pain: safery, efficacy and ventilatory responses to carbon dioxide. Anesth Analg 1988; 67: 137-43.

2 Chadwick HS, Ready LB. Intrathecal and epidural morphine sulfate for postcesarean analgesia - a clinical comparison. Anesthesiology 1988; 68: 925-9.

3 Abouleish $E$, Rawal $N$, Fallon $K$, Hernandez $D$. Combined intrathecal morphine and bupivacaine for cesarean section. Anesth Analg 1988; 67: 370-4.

4 Sun H-L, Wu C-C, Lin M-S, Chang C-F, Mok MS. Combination of low-dose epidural morphine and intra- muscular diclofenac sodium in postcesarean analgesia. Anesth Analg 1992; 75: 64-8.

5 Pavy TJG, Gambling DR, Merrick P, Douglas MJ. Indomethacin potentiates subarachnoid morphine analgesia following cesarean section. Anesth Analg 1993; 76: S325.

6 Mok MS, Tzeng JI. Intramuscular ketorolac enhances the analgesic effect of low dose epidural morphine. Anesth Analg 1993; 76: S269.

7 Kehlet $H$. Postoperative pain relief - what is the issue? (Editorial) Br J Anaesth 1994; 72: 375-8.

8 Kehlet $H, D a b l J B$. The value of "multimodal" or "balanced analgesia" in postoperative pain treatment. Anesth Analg 1993; 77: 1048-56.

$9 \mathrm{Dahl} J B$, Keblet $H$. The value of pre-emptive analgesia in the treatment of postoperative pain. $\mathrm{Br} \mathbf{J}$ Anaesth 1993; 70: 434-9.

10 Coderre TJ, Katz J, Vaccarino AL, Melzack $R$. Contribution of central neuroplastcity to pathological pain: review of clinical and experimental evidence. Pain 1993; 53: 259-85.

11 Woolf $C J$, Chong $M-S$. Preemptive analgesia - treating post-operative pain by preventing the establishment of central sensitization. Anesth Analg 1993; 77: 362-79.

12 Nègre I, Guéneron JP, Jamali SJ, Monin S, Ecoffey C. Preoperative analgesia with epidural morphine. Anesth Analg 1994; 79: 298-302.

13 Briggs GG, Freeman RK, Yaffe SJ. Drugs in Pregnancy and Lactation, 3rd ed. Baltimore, Maryland: Williams and Wilkins, 1990.

14 Bjune K, Stubbaug A, Dodgson MS, Breivik H. Additive analgesic effect of codeine and paracetamol can be detected in strong, but not moderate, pain after Caesarean section. Baseline pain-intensity is a determinant of assay-sensitivity in a postoperative analgesic trial. Acta Anaesthesiol Scand 1996; 40: 399-407.

15 Wright CE III, Antal EJ, Gillespie WR, Albert KS Ibuprofen and acetaminophen kinetics when taken concurrently. Clin Pharmacol Ther 1983; 34: 707-10.

16 Trotter TN, Hayes-Gregson P, Robinson S, Cole L, Coley S, Fell $D$. Wound infiltration of local anaesthetic after lower segment Caesarean section. Anaesthesia 1991; 46: 404-7.

17 Ganta R, Samra SK, Maddineni VR, Furness G. Comparison of the effectiveness of bilateral ilioinguinal nerve block and wound infiltration for postoperative analgesia after Caesarean section. Br J Anaesth 1994; 72: 229-30.

18 Rosaeg OP, Lindsay MP. Epidural opioid analgesia after Caesarean section: a comparison of patient-controlled analgesia with meperidine and single bolus injecton of morphine. Can J Anaesth 1994; 41: 1063-8.

19 Moiniche S, Hjortso NC, Hansen BL, et al. The effect of balanced analgesia on early convalescence after major 
orthopaedic surgery. Acta Anaesthesiol Scand 1994; 38: 328-35.

20 Moiniche S, Bïlow S, Hesselfeldt P, Hestbak A, Keblet $H$. Convalescence and hospital stay after colonic surgery with balanced analgesia, early oral feeding, and enforced mobilisation. Eur J Surg 1995; 161: 283-8.

21 Stenkamp SJ, Easterling TR, Chadwick HS. Effect of epidural and intrathecal morphine on the length of hospital stay after cesarean section. Anesth Analg 1989; 68: 66-9.

22 Burrows WR, Gingo AJ Jr, Rose SM, et al. Safety and efficacy of early postoperative solid food consumption after cesarean section. J Reprod Med 1995; 40: 463-7.

23 LaRosa JA, Saywell RM Jr, Zollinger TW, Oser TL, Erner $B K, M c$ Clain $E$. The incidence of adynamic ileus in postcesarean patients. Patient-controlled analgesia versus intramuscular analgesia. J Reprod Med 1993; 38: 293-300.

24 Chaney $M A$. Side effects of intrathecal and epidural opioids. Can J Anaesth 1995; 42: 891-903. 